\title{
RA?EGA
}

O ESPAÇO GEOGRÁFICO EM ANÁLISE

\section{FATORES DE PERTURBAÇÃO IDENTIFICADOS EM ÁREA DE PROTEÇÃO AMBIENTAL CORUMBATAÍ-BOTUCATU-TEJUPÁ, PERÍMETRO BOTUCATU, ESTADO DE SÃO PAULO}

\section{DISTURBANCE FACTORS IDENTIFIED IN THE ENVIRONMENTAL PROTECTION AREA CORUMBATAÍ-BOTUCATU-TEJUPÁ, BOTUCATU-PERIMETER, STATE OF SÃO PAULO}

Ronaldo Alberto Pollo ${ }^{1}$, César de Oliveira Ferreira Silva ${ }^{2}$, Lincoln Gehring Cardoso ${ }^{3}$, Luís Gustavo Frediani Lessa $^{4}$

\section{RESUMO}

As imagens de satélite de alta resolução espacial se tornaram muito importantes na análise, interpretação e quantificação das transformações ambientais ocorridas ao longo do tempo, permitindo o monitoramento da dinâmica do uso e ocupação do solo, e o monitoramento de áreas protegidas por lei, promovendo instrumentos para um desenvolvimento sustentável, que concilia a produção agrícola e a proteção dos recursos naturais. 0 presente trabalho é uma análise espacial dos fatores de perturbação e seus potenciais impactos ambientais nos recursos hídricos identificados na Área de Proteção Ambiental (APA) Corumbataí-Botucatu-Tejupá - Perímetro Botucatu-SP em sua porção localizada dentro do município de São Manuel, Estado de São Paulo, por meio de imagens digitais do Google Earth Pro dos anos de 2010 e 2016. Identificou-se oito áreas com fatores de perturbação (A, B, C, D, E, F, G, H) onde foram detectados focos de desmatamento e avanço de pastagem e monoculturas sobre áreas de preservação ambiental, tais como nascentes e locais de potencial recarga de aquífero. Essas ocupações irregulares geram impactos na produção de água, tais como impermeabilização do solo, escoamento superficial e erosão com transporte de sedimentos. Esse procedimento é aplicável à municípios de pequeno e médio porte para detecção e monitoramento de inconformidades ambientais.

Palavras chave: geoprocessamento; Google Earth; impactos ambientais.

\section{ABSTRACT}

The satellite images with high spatial resolution have become very important in the action of analysis, interpretation and quantification of the environmental transformations that have occurred over time, looking for the monitoring of land use and land cover dynamics on protected areas by law, thus facilitating the search for sustainable development and making it possible to reconcile agricultural production by the natural resources protection. The present work is a spatial analysis of the perturbation factors and their potential environmental impacts on the water resources identified in the Environmental Protection Area (EPA) - Botucatu-SP Perimeter this portion located within the municipality of São Manuel, State of São Paulo, through digital images of Google Earth Pro since the years of 2010 to 2016. It was identified eight areas with perturbation factors $(A, B, C, D, E, F, G, H)$, where it was possible to detect points of deforestation and the pasture and monoculture crops increase in areas of environmental preservation, such as springs and places of potential aquifer recharge. These irregular occupations generate impacts on water production, such as soil sealing, runoff and erosion with sediment transport. This procedure is applicable to municipalities of small and medium size to detect and monitor environmental nonconformities.

Keywords: geoprocessing; Google Earth; environmental impacts.

\footnotetext{
${ }^{1}$ Universidade Estadual Paulista "Júlio de Mesquita Filho", Botucatu/SP, email: ra.pollo@unesp.br

2 Universidade Estadual Paulista "Júlio de Mesquita Filho", Botucatu/SP, email cesaroliveira.f.silva@gmail.com

3 Universidade Estadual Paulista "Júlio de Mesquita Filho", Botucatu/SP, email: lincoln-gehring.cardoso@unesp.br

${ }^{4}$ Universidade Estadual Paulista "Júlio de Mesquita Filho", Botucatu/SP, email: gustavo.lessa@ unesp.br
} 


\section{FATORES DE PERTURBAÇÃO IDENTIFICADOS EM ÁREA DE PROTEÇÃO AMBIENTAL CORUMBAí- BOTUCATU-TEJUPÁ, PERÍMETRO BOTUCATU, ESTADO DE SÃO PAULO}

\section{INTRODUÇÃo}

As Áreas de Proteção Ambiental (APAs), segundo Machado (2016), são instituídas por lei para assegurar a proteção e conservação da qualidade ambiental da flora, fauna, os atributos estéticos e culturais, visando à biodiversidade e a sustentabilidade a algumas extensas áreas naturais, adequando e orientando o desenvolvimento das várias atividades humanas a regras específicas. Nesse contexto, Decreto Estadual no 20.960/83, São Paulo (1983) criou a APA Corumbataí-Botucatu-Tejupá, conhecida como APA Cuesta, com o objetivo de proteger fragmentos significativos da flora e fauna regional, rios, córregos e o Aquífero Guarani, que, como ressaltado em estudo regional de Alburquerque Filho et al (2011), possui nestas áreas afloramentos de mananciais de água doce, tornando-se importantes zonas de recarga deste sistema de reconhecida importância estratégica a nível mundial. São Paulo (2011) estabelece uma série de fatores de perturbação (que são evidências e impulsos para impactos ambientais) a serem monitorados na APA que podem ser resumidos em uso e ocupação da terra irregular.

A análise e interpretação das imagens de satélite de alta resolução espacial se tornaram muito importantes no monitoramento das transformações ambientais, servindo de apoio à tomada de decisões, possibilitando alternativas inteligentes para um melhor planejamento ambiental.

Moreira et al. (2007) avaliam que imagens digitais com alta resolução espacial disponibilizados pelo Google Earth permitem a visualização e caracterização de informações espaciais de diferentes locais com precisão adequada a aplicações de escala regional (municipal ou estadual) e pontuais (propriedades rurais, bairros e distritos). Simon e Trentin (2009), avaliando as potencialidades das imagens do Google Earth, afirmaram que estas se mostraram adequadas na elaboração de séries temporais de uso da terra com identificação de padrões recentes.
Estas imagens fornecem com detalhes possibilidades de análise geoespacial do uso e ocupação da terra, sendo possível distinguir, delimitar e estudar diferentes elementos da superfície da Terra (Panniza, Fonseca, 2011). Esses elementos diferem entre si por suas cores, formas, tamanhos e texturas, sendo as cores resultado de composições coloridas de imagens e resultam da interação da energia eletromagnética com os objetos terrestres, tornando-se esse aspecto a base da fotointerpretação de imagens de satélite de alta resolução espacial (AKBARI, ROSE, TAHA, 2003; CARDOSO, AQUINO, 2014). Piroli e Zanata (2014), sugerem a utilização de imagens de alta resolução espacial para o monitoramento das áreas de preservação permanentes (APPs), categoria especial de área protegida instituída em Brasil (2012) e considerada uma classe de ecossistema essencial aos processos biológicos, hidrológicos e socioambientais Borges et al., (2011), pois permitem a identificação precisa das mudanças ocorridas ao longo do tempo.

O presente trabalho é uma análise espacial dos fatores de perturbação e seus potenciais impactos ambientais nos recursos hídricos identificados na Área de Proteção Ambiental (APA) perímetro Botucatu que estão contidas no município de São Manuel-SP. Através do estudo da cobertura e o uso das terras a partir de análise e interpretação visual de imagens orbitais temporais georreferenciadas de alta resolução espacial do Google Earth Pro, foram identificadas oito áreas $(A, B, C, D, E, F, G, H)$ com evidências de fatores de perturbação aos recursos hídricos.

A Figura 1 apresenta a localização da porção da APA Perímetro Botucatu-SP pertencente ao município de São Manuel-SP e as áreas de interesse definidas para coleta de fatores de perturbação. A localização da APA perímetro Botucatu-SP ocupa dentre outros municípios, uma área correspondente a $4 \%$ no município de São Manuel-SP, com 3.237 hectares, ou seja, $32,37 \mathrm{~km}^{2}$. 
POLLO, R. A., SILVA, C. O. F., CARDOSO, L. G., LESSA, L. G. F.

\section{FATORES DE PERTURBAÇÃO IDENTIFICADOS EM ÁREA DE PROTEÇÃO AMBIENTAL CORUMBAÍ- BOTUCATU-TEJUPÁ, PERÍMETRO BOTUCATU, ESTADO DE SÃO PAULO}

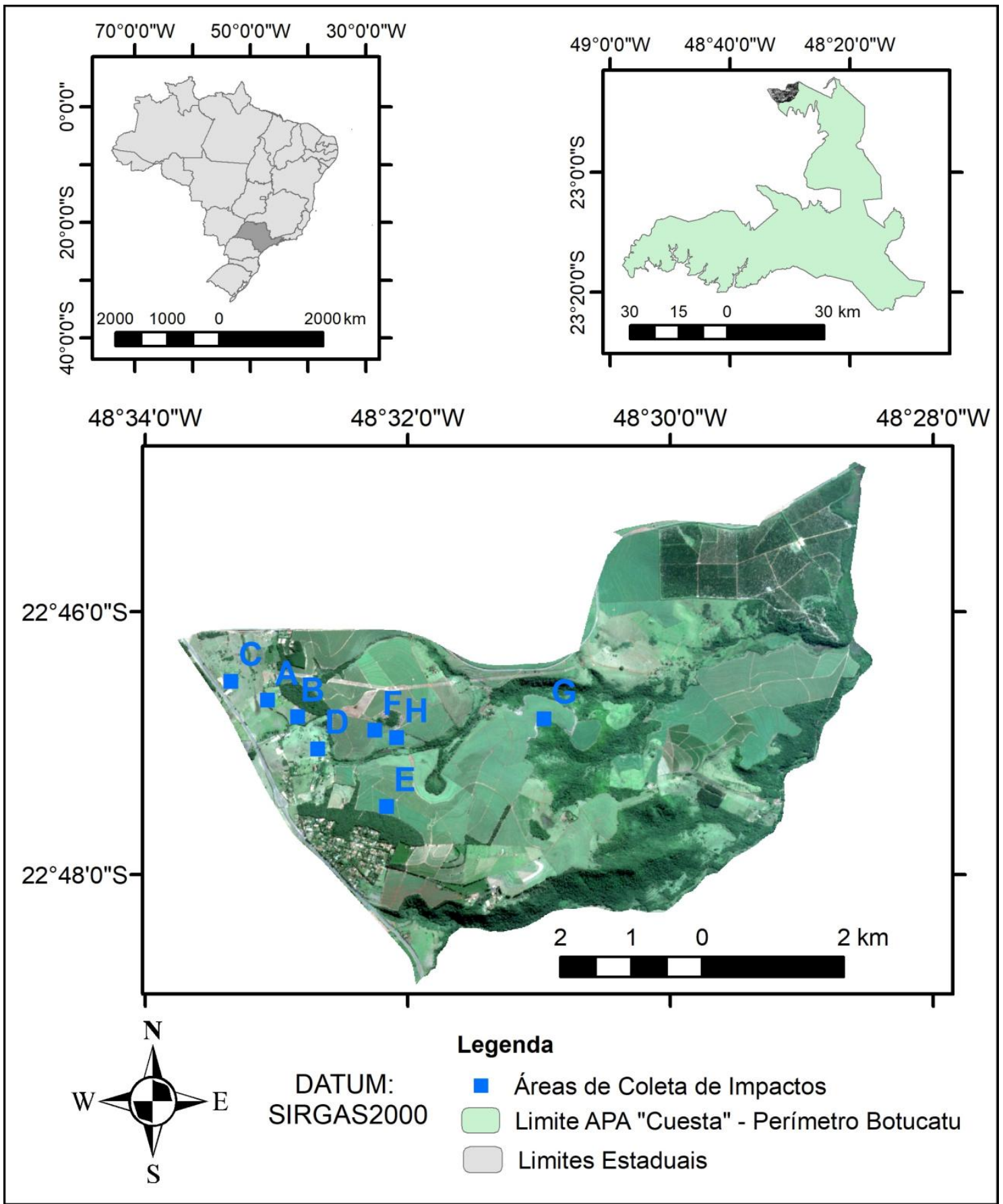

Figura 1 - Área de Proteção Ambiental - APA dentro do município de São Manuel-SP, com as áreas de coleta de fatores de perturbação (indicados por letras). Fonte de dados vetoriais: MMA (2018)

\section{MATERIAL E MÉTODOS}

Para a delimitação da área de estudo foram utilizadas cartas planialtimétricas do IBGE na escala 1:50.000, com equidistância de 20 metros referentes a Pratânia, folha: SF-22-Z-B-V4 do ano de 1969; Botucatu, folha: SF-22-R-IV-3 de 1969 e Barra Bonita, folha: SF-22-Z-B-VI-1 de
1974 (IBGE, 2018). A utilização das cartas em diferentes datas deve-se a disponibilização do material editado pelo IBGE nestas datas. De posse do Sistema de Informação Geográfica QGis com código aberto para aplicações geoespaciais, foi traçado o limite da área de estudo, realizado o georreferenciamento e a avaliação da área da 


\section{FATORES DE PERTURBAÇÃO IDENTIFICADOS EM ÁREA DE PROTEÇÃO AMBIENTAL CORUMBAí- BOTUCATU-TEJUPÁ, PERÍMETRO BOTUCATU, ESTADO DE SÃO PAULO}

APA perímetro Botucatu-SP, apenas da área contida no município de São Manuel e avaliação de algumas áreas dentro do processo de degradação ambiental. As cartas topográficas, sendo documentos oficiais dos órgãos públicos, também serviram de base cartográfica na consulta para a identificação de nascentes e córregos.

Para identificação e avaliação espacial do uso e ocupação da terra foram utilizadas imagens do banco de imagens de alta resolução espacial do Google Earth Pró (2018), que permitem alterações de escala com ampliações nas datas de 25/07/2010 e 17/06/2016, que auxiliam a interpretação visual das imagens. A análise visual consiste na investigação de elementos da paisagem e seu reconhecimento relacionando (textura, forma, padrão, cores), diante das convergências de evidências, detalhes espaciais e a significância dos alvos. Avaliou-se o uso e ocupação da terra nas áreas de interesse nos anos de 2010 e 2016.

Analisou-se evidências de fatores de perturbação previstas em São Paulo (2011) e através delas projetou-se impactos ambientais gerados por esses fatores de perturbação.

\section{RESULTADOS E DISCUSSÃO}

As coordenadas geográficas dos pontos analisados neste trabalho, são referenciais tomados próximo ao centro das áreas de interesse.

A Figura 2 que apresenta as áreas " $A$ ", "B" e "C" em 2010 e 2016, foi possível observar com a utilização do zoom, a área " $A$ " no de 2010 (coordenadas geográficas 4833'09"W e $222^{\circ} 46^{\prime} 42^{\prime \prime S}$ ) que ao redor de uma nascente, que alimenta um importante manancial destinado ao abastecimento público da área urbana do município de São Manuel-SP, há uma grande área úmida tipo banhado de coloração verde escura. Entende-se aqui por nascente o afloramento do lençol freático, quando com baixa vazão, capaz apenas molhar o terreno, e quando grande, pode originar o tipo com acúmulo inicial, comum quando a camada impermeável fica paralela à parte mais baixa do terreno e, estando próximo à superfície, acaba por formar um lago Calheiros (2009), citado por (SANTOS et al., 2012).

Já na imagem de 2016, ainda em " $A$ " (Figura 2), a nascente apresenta menor acúmulo de água, com coloração um pouco mais clara e menor área úmida, estando desprovida de vegetação ciliar, sem vegetação nos 50 metros de raio para nascentes e os 30 metros ao longo do rio, para rios até 10 metros de largura, contrariando o estabelecido pela legislação brasileira no tocante as Áreas de Preservação Permanentes-APPs (BRASIL, 2012).

Pollo (2017), após trabalhos de campo nesta área, afirmou que o entorno da nascente está sendo ocupada totalmente por pastagem, não existindo uma estrutura de isolamento, além de existir bem próximo, centro de manejo para criação de bovinos com divisão de piquetes, onde o gado tem livre acesso a nascente, como indicado pelas evidências de pisoteio ao seu redor, pois a mesma está sendo utilizada como bebedouro.

Para Lollo et al., (2019) em geral, a pecuária praticada em áreas de pastagem provoca o comprometimento da qualidade dos recursos hídricos na forma direta, com o gado tendo acesso aos corpos hídricos e indiretamente, com o carreamento de sedimentos para os corpos d'água. 


\section{FATORES DE PERTURBAÇÃO IDENTIFICADOS EM ÁREA DE PROTEÇÃO AMBIENTAL CORUMBAÍ- BOTUCATU-TEJUPÁ, PERÍMETRO BOTUCATU, ESTADO DE SÃO PAULO}

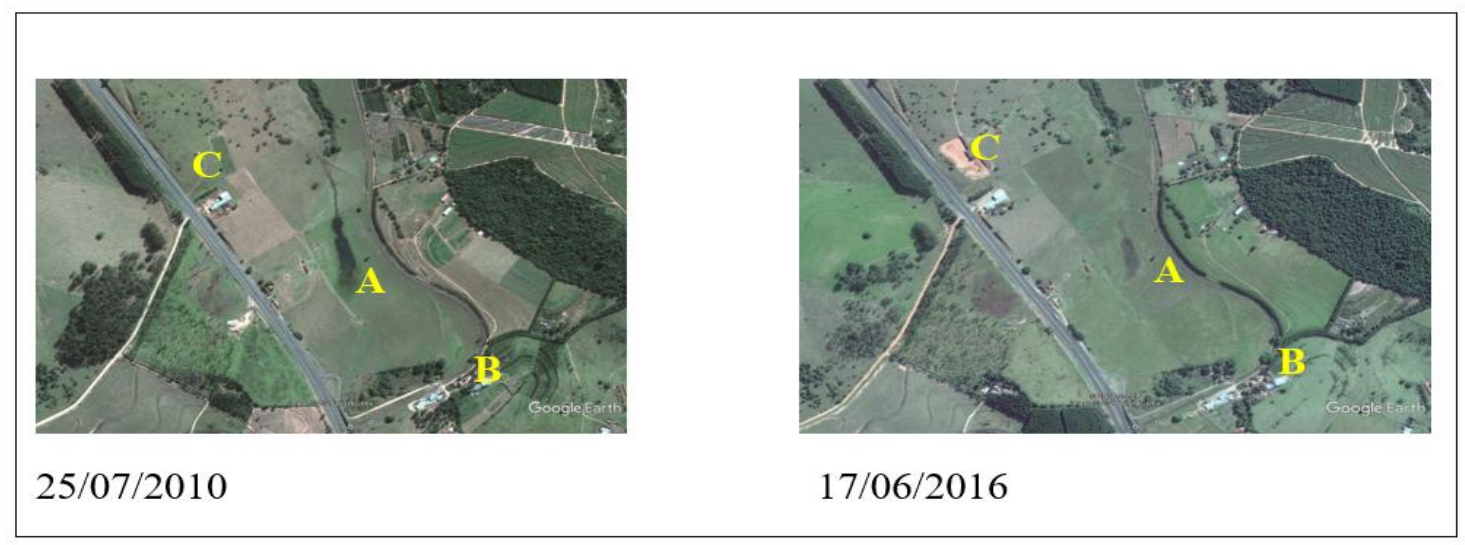

Figura 2 - Localização das áreas "A", "B" e “C". Fonte: Google Earth (2018).

$\mathrm{Na}$ área em “B" (4832'55"W; 2246'51"S), também apresentada na Figura 2, há uma ferrovia (antiga FEPASA), hoje Estrada Ferro Paulista S/A, tem em seu histórico, neste trecho, muitas ocorrências de descarrilamentos de trens carregados com combustíveis, tipo óleo diesel com vazamentos no local segundo FM Integração (2012), evidenciando possível contaminação em área de influência de recarga do Sistema Aquífero Guaraní-SAG, justificando assim um constante monitoramento para a manutenção de seu equilíbrio.

Ainda na Figura 2, há uma ocorrência em "C" (4833'25"W; 2246'32"S) um grande corte no terreno no ano de 2016 com área de 1 hectare de solo exposto, com coloração rosa clara e um desnível de aproximadamente 4 metros em relação ao terreno onde se procedeu a retirada de terra (área de empréstimo) utilizada para elevação de passagem de nível de uma rodovia que faz limite com a APA e com visitas atuais sob trabalho de campo, este ambiente encontra-se ainda degradado, necessitando de recuperação, onde também pôde ser visualizado com zoom e ao nível do solo em qualquer ângulo, com situação "in loco” pela Rodovia Marechal Rondon (SP-300), ao lado da ocorrência, na função arraste Street View, pela forma tridimensional disponível no Google Earth.

A área "D" (4832'46"W e 2247'07"S), exposta na Figura 3, apresentou predomínio de pastagens no ano de 2010, com algumas intervenções como a construção de terraços pontuais a oeste da imagem, um pouco distante da área perturbada, foram locados com objetivo de conter e/ou direcionar a água de chuva, porém, esta área por estar dividida em pequenas propriedades rurais, não apresentou práticas conservacionistas de solo em toda sua área, evidenciado pela ausência de curvas de nível, o que culminou, em 2016 em erosão tipo voçoroca ocasionada pela concentração do fluxo da água para uma mesma direção, causando prejuízos em estrada rural, dificultando o tráfego local e problemas nos corpos d'água, vindo a assorear uma nascente e uma represa (visualizada em 2010 na região sudeste da imagem de satélite) do ribeirão Igualdade. 


\section{FATORES DE PERTURBAÇÃO IDENTIFICADOS EM ÁREA DE PROTEÇÃO AMBIENTAL CORUMBAí- BOTUCATU-TEJUPÁ, PERÍMETRO BOTUCATU, ESTADO DE SÃO PAULO}

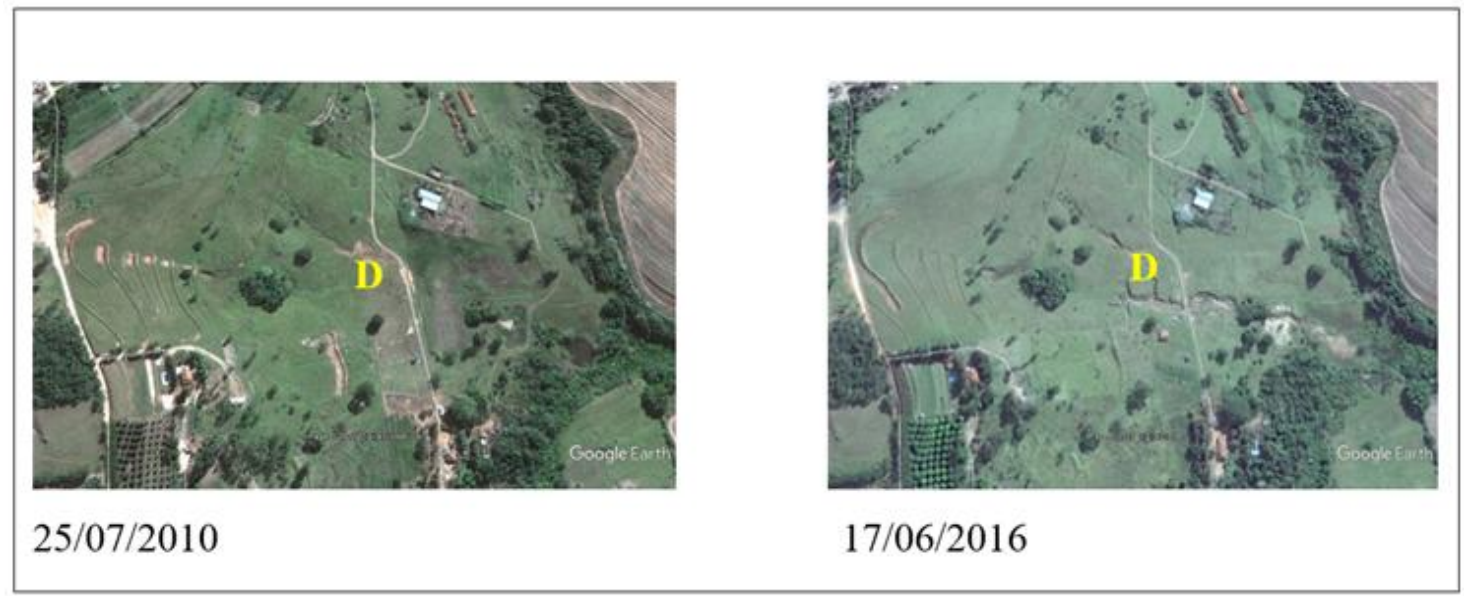

Figura 3 - Em 2010, ausência de conservação de solo mais efetiva; em "D" no ano de 2016, ocorrência da voçoroca e o assoreamento dos corpos d'água. Fonte: Google Earth (2018).

Esta área encontra-se sobre LATOSSOLO VERMELHO-AMARELO (LVA) que, segundo Neiva Júnior et al., (2015), são representadas por arenitos finos a médio, ocorrendo sobre rochas da formação Botucatu, sendo suscetíveis aos processos erosivos.

A Figura 4, apresenta a área " $E$ ", nas coordenadas geográficas 4832'07"W e 2247'31"S, que no ano de 2010 apresentou muitos indivíduos florestais espalhados por uma área que corresponde aproximadamente a 30 hectares, ocupada por pastagem e identificadas como remanescentes da mata atlântica, sendo da mesma espécie das encontradas na divisa desta propriedade, num grande dossel preservado de Floresta Ombrófila Densa, São Paulo (2009), integrante do Bioma Mata Atlântica, na qual, em 2016, constatou-se a supressão destes indivíduos e o registro do momento na imagem mostrou ausência de fisionomia florestal e o processo de destoca da área na preparação para o plantio de cana-de-açúcar.

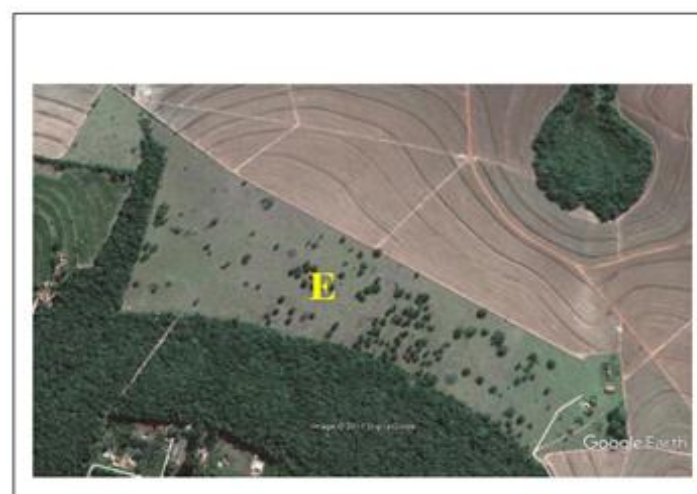

$25 / 07 / 2010$

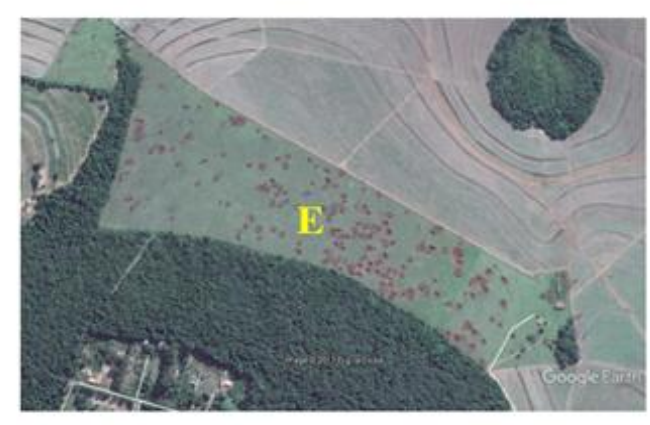

$17 / 06 / 2016$

Figura 4 - Área "E" em 2010 o registro dos indivíduos florestais e em 2016, a supressão e destoca da área. Fonte: Google Earth (2018).

A Figura 5, em “F” (48032'08”W; 2246'50"S), apresenta notável supressão de remanescentes florestais, com visão ampliada das características ambientais entre 2010 e 2016, evidenciando diminuição na densidade vegetativa com alterações e perdas de biodiversidade do exterior para o interior de um fragmento praticamente isolado de Floresta Ombrófila Densa, até então existente dentro de uma área circundada pela cultura da cana-de-açúcar, com 
POLLO, R. A., SILVA, C. O. F., CARDOSO, L. G., LESSA, L. G. F.

\section{FATORES DE PERTURBAÇÃO IDENTIFICADOS EM ÁREA DE PROTEÇÃO AMBIENTAL CORUMBAí- BOTUCATU-TEJUPÁ, PERÍMETRO BOTUCATU, ESTADO DE SÃO PAULO}

uma grande área em processo de regeneração, apresentando biomassa com aspecto seco e desta forma, demonstrando pouca intensidade de energia eletromagnética refletida por este tipo de alvo, já que as diferenças de leitura na faixa espectral das imagens são capazes de detectar a presença de diversos tipos de culturas, entre elas as sadias, queimadas por fogo ou não fotossinteticamente ativas chamadas de desidratadas (secas) devido a aplicações de defensivos. Por não apresentar indícios de queima da biomassa por fogo, mediante aspecto de material desidratado, apresentando coloração tipo palha seca, indica aplicação de herbicidas utilizados nesta cultura no combate as ervas daninhas, a qual necessita de um melhor planejamento para sua melhor proteção.

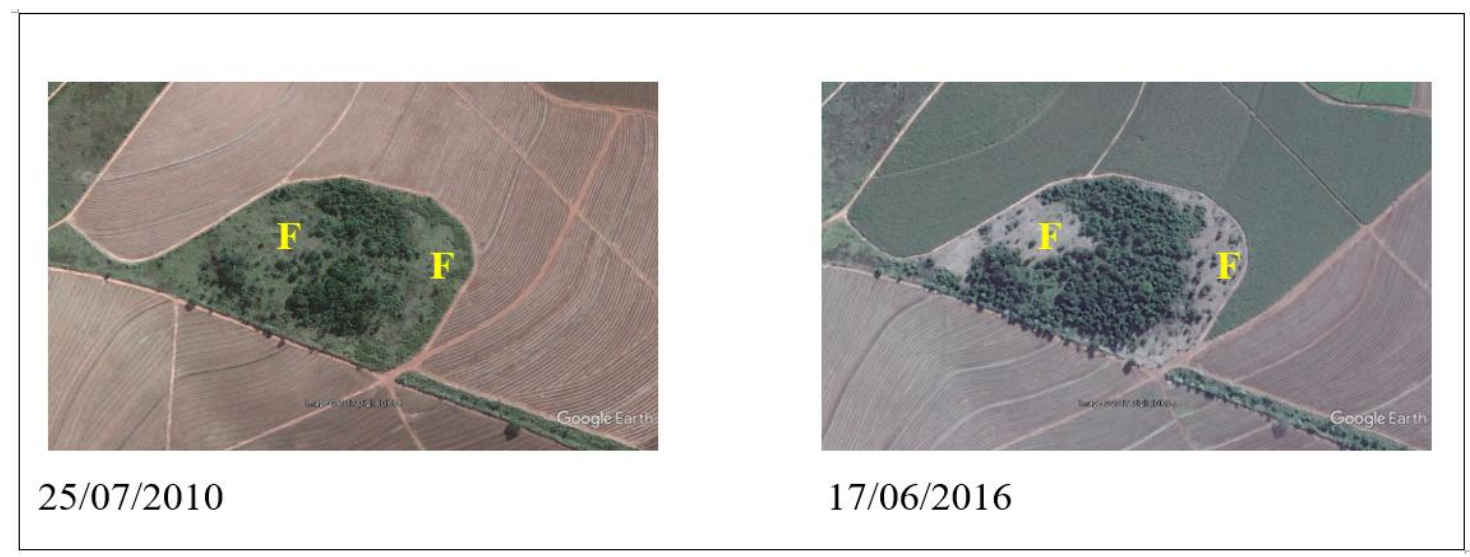

Figura 5 - Perda da biodiversidade em fragmento isolado de Floresta Ombrófila Densa em "F", causado pela aplicação de herbicidas em áreas vizinhas. Fonte: Google Earth (2018).

A utilização de herbicidas sem as técnicas de aplicação pode ser observada na Figura 6, em “G” (4831'09"W e 2246'47"S) no ano de 2016, em vários pontos, em área ocupada por Floresta Estacional Semidecidual, São Paulo (2009) do Bioma Mata Atlântica, onde os produtos utilizados na cultura da cana-de-açúcar não atingem somente o alvo (área destinada à cultura da cana-de-açúcar), ocorrendo como conseqüência à contaminação ambiental da vegetação lindeira (divisa), causada pela deriva nas aplicações, onde aparentemente apresentam um comportamento sem produção de fotossíntese, apresentando também aspecto de material desidratado com coloração tipo palha seca quando comparadas à imagem de 2010, mostrando um arranjo com continuidade na borda da vegetação em formato de mosaico. 


\section{FATORES DE PERTURBAÇÃO IDENTIFICADOS EM ÁREA DE PROTEÇÃO AMBIENTAL CORUMBAí- BOTUCATU-TEJUPÁ, PERÍMETRO BOTUCATU, ESTADO DE SÃO PAULO}

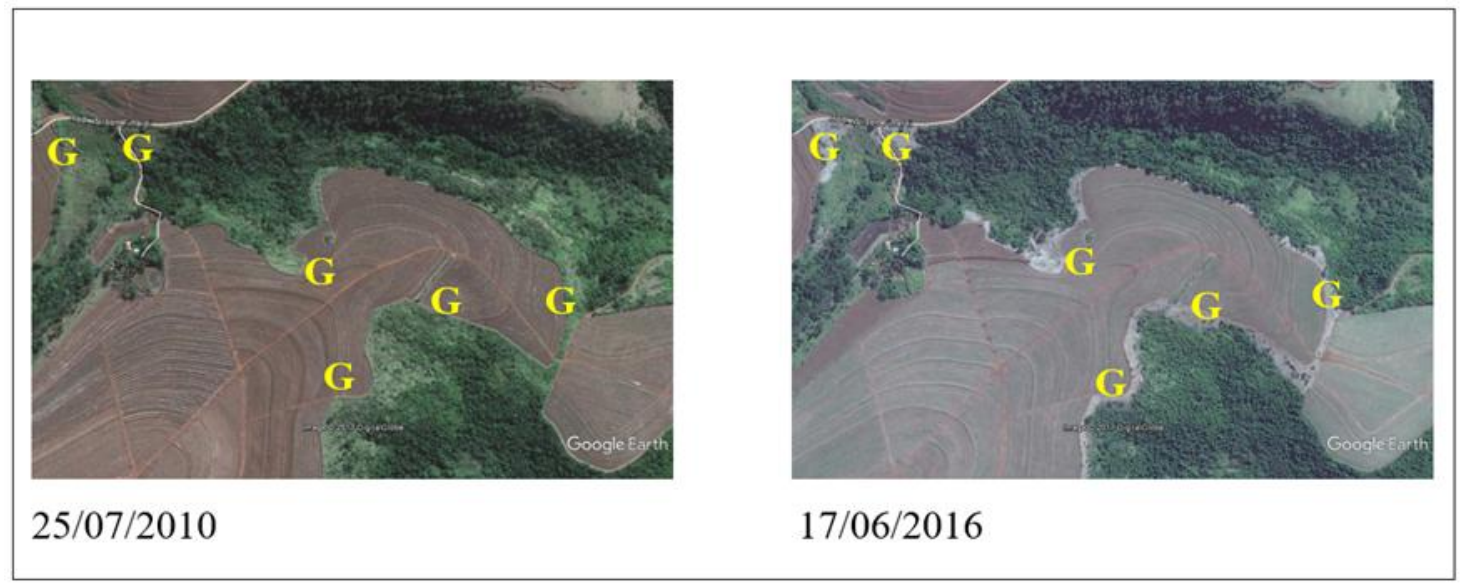

Figura 6 - Dessecação de vegetação lindeira ocasionada pela aplicação de herbicidas na cana-de-açúcar em “G”. Fonte: Google Earth (2018).

Identificou-se na Figura 7, no ano de 2016 em "H" (4832'08"W; 2247'03"S) a expansão do preparo de solo para o plantio da cana-de-açúcar dentro das Áreas de Preservação Permanentes em trecho à beira do ribeirão Igualdade-SP, sendo essa uma inconformidade com o atual Código Florestal Brasileiro (BRASIL, 2012), no tocante as Áreas de Preservação
Permanentes-APPs, que define 30 metros ao longo do rio, para rios até 10 metros de largura.

A redução da vegetação das áreas de preservação permanentes mediante o avanço no preparo de solo para a agricultura, fragilizam o leito do rio e representam modificações nas condições ambientais de toda a área e o retrocesso ao atendimento aos instrumentos legais existentes.

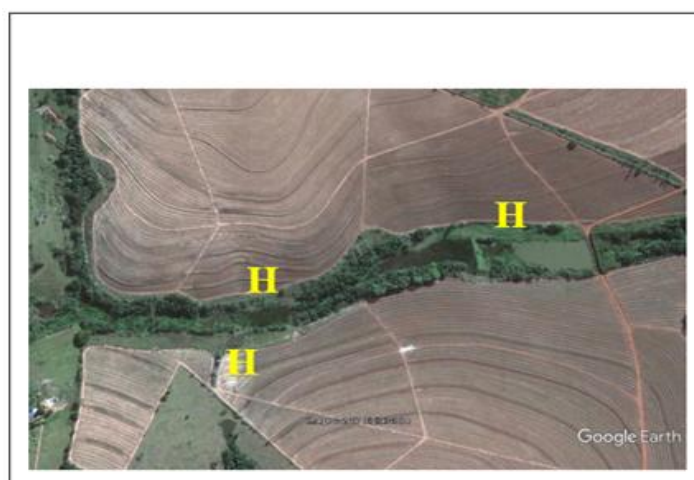

$25 / 07 / 2010$

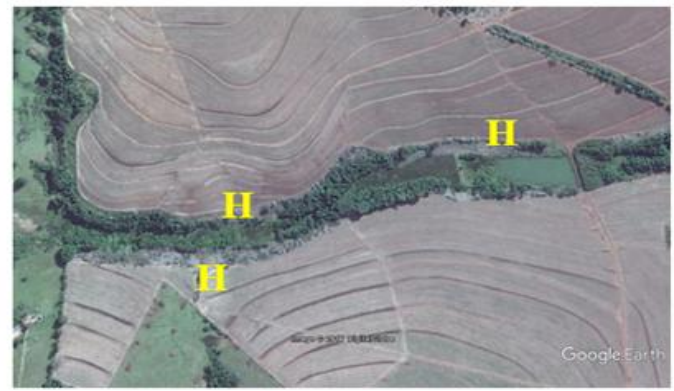

$17 / 06 / 2016$

Figura 7 - Preparo do solo nas APPs do ribeirão Igualdade-SP. Fonte: Google Earth (2018).

As evidências de fatores de perturbação identificados projetam cenários de avanço da degradação ambiental das regiões de nascentes, recarga de aquífero e margens de corpos d'água, gerando risco de escoamento superficial, impermeabilização do solo, erosão e abertura de áreas de solo exposto.

\begin{abstract}
Assim, fazem-se necessárias intervenções de gestão ambiental para regularizar a qualidade ambiental em áreas de impacto aos recursos hídricos. Sugere-se que sejam feitos o reflorestamento das áreas de preservação permanente e conservadas para garantir segurança hídrica à região, como estipulado em Brasil (2012), assim como
\end{abstract}




\section{FATORES DE PERTURBAÇÃO IDENTIFICADOS EM ÁREA DE PROTEÇÃO AMBIENTAL CORUMBAí- BOTUCATU-TEJUPÁ, PERÍMETRO BOTUCATU, ESTADO DE SÃO PAULO}

monitorar potenciais contaminadores próximos as nascentes, áreas de recarga de aquífero e do rio e controle ambiental do uso e ocupação do solo, com especial atenção quanto ao uso abusivo de defensivos agrícolas próximos a APPs.

O procedimento de monitoramento aqui apresentado é aplicável a municípios de pequeno e médio porte que buscam instrumentos de detecção e averiguação remota de inconformidades ambientais, como é o caso de São Manuel, Estado de São Paulo.

\section{CONCLUSÕES}

A utilização de imagens orbitais de alta resolução espacial do Google Earth com sua capacidade de alterações de escalas, sob o registro de avaliações históricas, possibilitaram a ampliação e a riqueza de detalhes do espaço geográfico analisado, permitindo obter respostas mais precisas das informações sobre a ocupação do solo e a degradação ambiental gerada pelas atividades humanas ocorrida em várias áreas da porção da APA Corumbataí-Botucatu-Tejupá, contida no município de São Manuel-SP.

Os principais impactos ambientais identificados foram focos de desmatamento e avanço de pastagem e monoculturas sobre áreas de preservação ambiental, tais como nascentes e locais de potencial recarga de aquífero. A identificação e análise visual simplificada destas áreas gera subsídios para sugestão de ações de gestão ambiental.

As alterações na cobertura vegetal ocasionadas pelas atividades agrícolas tornaram a região suscetível a processos de degradação ambiental gerando fragilização dos recursos hídricos, evidenciando ações incompatíveis com as restrições legais instituídas para estas áreas, como a ocupação irregular da terra em áreas de preservação ambiental e o assoreamento de corpos hídricos entre o período de 2010 e 2016.

\section{REFERÊNCIAS}

AKBARI, H.; ROSE, L.S.; TAHA, H. Analyzing the land cover of an urban environment using highresolution orthophotos. Landscape and Urban Planning, v. 63, p. 1-14, 2003. Disponível em:

<https://www.sciencedirect.com/science/article/ pii/S0169204602001652?via\%3Dihub.>. Acesso em: 17 abr. 2018.

ALBUQUERQUE FILHO, J. L.; CARVALHO, A. M.; BARBOSA, M. C.; IKEMATSU, P.; FREITAS, C. G. L.; MONTEIRO, A. C. M. C.; IRITANI, M.; PRESSINOTTI, M. M. N.; ROCHA, G., TAKASHI; SILVA, M. P. M.; KOVACS, A.; CAMARGO, G. G. Subsídios ao Plano de Desenvolvimento e Proteção Ambiental da área de afloramento do Sistema Aquífero Guarani no Estado de São Paulo. São Paulo: Instituto de Pesquisas Tecnológicas, 2011.

BRASIL. Lei $n^{\circ} 12.727$ de 17 de outubro de 2012 . Altera a Lei no 12.651, de 25 de maio de 2012, que dispõe sobre a proteção da vegetação nativa. Diário Oficial da República Federativa do Brasil. Poder Legislativo, Brasília, 18 out. 2012.

BORGES, L. A. C.; REZENDE, J. L. P.; PEREIRA, J. A. A.; COELHO JÚNIOR. M. L.; Barros, D. A. Áreas de preservação permanente na legislação ambiental brasileira. Ciência Rural, v. 41, n. 7, p. 1202-1210, 2011. Disponível em:< http://www.scielo.br/pdf/cr/v41n7/a5611cr4051 .pdf>. Acesso em: 12 abr. 2018.

CARDOSO, J.; AQUINO, C. M. S. Mapeamento atual do uso e cobertura das terras da sub-bacia do riacho Roncador em Timon (MA) utilizando imagens do Google Earth. Revista OKARA: Geografia em debate, v.8, n.2, p. 328-343, 2014. Disponível em: file://C:/Users/Ronaldo/Downloads/1993744022-1-PB.pdf>. Acesso em: 20 mar. 2018.

CALHEIROS, R. O. Preservação e recuperação das nascentes de água e vida (Cadernos da Mata Ciliar). São Paulo: Secretaria de Meio Ambiente, 2009. 35p.

FM INTEGRAÇÃO. Trem descarrilou em São Manuel houve vazamentos e veja as fotos. 2012. Disponível em: 


\section{FATORES DE PERTURBAÇÃO IDENTIFICADOS EM ÁREA DE PROTEÇÃO AMBIENTAL CORUMBAí- BOTUCATU-TEJUPÁ, PERÍMETRO BOTUCATU, ESTADO DE SÃO PAULO}

https: $</ /$ www.fmintegracao.com.br/fmnoticias/11-noticiario/925-trem-descarrilou-emsao-manuel-veja-as-fotos>. Acesso em 30 jan. 2019.

GOOGLE EARTH PRO. Google Inc, 2018. Disponível em:<earth.google.com/>. Acesso em: 10 fev. 2018.

INSTITUTO BRASILEIRO DE GEOGRAFIA E ESTATÍSTICA. Carta topográfica: folhas PratâniaSF-22-Z-B-V-4, Botucatu- SF-22-R-IV-3 e Barra Bonita- SF-22-Z-B-VI-1. Serviço do IBGE on line. Mapeamento Topográfico. Escala 1:50.000. Acesso em 10/01/2018. Disponível em: https://www.ibge.gov.br/geocienciasnovoportal/cartas-e-mapas/folhastopograficas/15809-folhas-da-carta-dobrasil.html?edicao=16041.

LOLLO, J. A.de; NEVES, M. de PAULA, ARANTES, L. T.; LIMA, C. G. da R.; LORANDI, R. Mudanças de uso e cobertura da terra e degradação ambiental em bacias hidrográficas. In: Juliana Heloisa Pinê Américo-Pinheiro; Sandra Benini (orgs.). Bacias hidrográficas: fundamentos e aplicações. Tupã: Editora ANAP, 2019. Cap.1, 1742.

MACHADO, P. A. L. Direito Ambiental Brasileiro. São Paulo: Malheiros Editores, 2016.

MINISTÉRIO DO MEIO AMBIENTE - MMA. i3geo MMA - Acervo de Mapas. Disponível em: <http://mapas.mma.gov.br/i3geo/mma/openlay ers.htm?2bmt2qqtselp7fciohpj-451mi1>. Acesso 9 mai. 2018.

MOREIRA, M. A.; BARROS, M.A.; DE FARIA, V. G. C.; ADAMI, $M$. Tecnologia de informação: imagens de satélite para o mapeamento de áreas de café de Minas Gerais. Informe Agropecuário, v. 28 , n. 241 , p. $27-37,2007$. Disponível em: < http://www.dsr.inpe.br/laf/cafesat/artigos/Tecn ologialnformacaoCafeMG.pdf>. Acesso em: 12 mar. 2018.
NEIVA JÚNIOR, E., ROCHA, W. W.; PIRES, B. S.; FARNEZI, M. M. M.; DIAS JUNIOR, M. S.; FREITAS, D. F. B.; SILVA, E. B.; CARVALHO, G. A. O. Compressiblity and penetrability of latossolo vermelho-amarelo distrófico (oxisol) under varied management systems and land uses. Revista Brasileira de Ciência do Solo, v. 39, p. 86-93, 2015. Disponível em: < http://www.scielo.br/scielo.php?script=sci_artte xt\&pid=S0100-06832015000100086 >. Acesso em: 14 abr. 2018.

PANIZZA, A. C.; FONSECA, F. P. Técnicas de Interpretação Visual de Imagens. GEOUSPEspaço e Tempo, São Paulo, n. 30, p. 30 - 43, 2011. Disponível em: < http://www.journals.usp.br/geousp/article/viewF ile/74230/77873>. Acesso em: 14 abr. 2018.

PIROLI, E.L.; ZANATA, J. M. Hydrography update and study of the permanent preservation areas from a remote sensing of high spatial resolution. Brazilian Journal of Applied Technology for AgriculturalScience, Guarapuava, v. 7, n. 1, 7-16. 2017. Disponível em: < https://revistas.unicentro.br/index.php/repaa/ar ticle/view/2883/2238>. Acesso em: 14 abr. 2018.

POLLO, R. A. Mapeamento do Zoneamento da Bacia Hidrográfica do Ribeirão Paraiso, São Manuel-SP, visando o Planejamento e Gestão Ambiental. 2017. 145f. (Tese de Doutorado em Agronomia-Energia na Agricultura) - Faculdade de Ciências Agronômicas, Universidade Estadual Paulista, Botucatu, 2017.

SANTOS, W.L.; NASCIMENTO, F.I.C.; ARCOS, F.O. Uso da terra versus áreas de nascentes: análise de impactos com utilização de geotecnologias no sudoeste amazônico - Acre - Brasil. Revista Geonorte, Edição Especial, v.2, n.4, p.1777 1787, 2012. Disponível em: < file://C:/Users/Ronaldo/Downloads/2232-16525-1-10-20160223.pdf>. Acesso em: $21 \mathrm{fev}$. 2018. 
POLLO, R. A., SILVA, C. O. F., CARDOSO, L. G., LESSA, L. G. F.

\section{FATORES DE PERTURBAÇÃO IDENTIFICADOS EM ÁREA DE PROTEÇÃO AMBIENTAL CORUMBAí- BOTUCATU-TEJUPÁ, PERÍMETRO BOTUCATU, ESTADO DE SÃO PAULO}

SÃO PAULO. Decreto Estadual № 20.960, de 8 de junho de 1983. Área de Proteção Ambiental: São Paulo. Diário Oficial v.96, n. 2, 1983. Disponível em:

<http://www.ambiente.sp.gov.br/apas/20960.ht m> .Acesso em: 23 jan..2017.

SÃO PAULO. Secretaria do Meio Ambiente do Estado de São Paulo. Instituto Florestal. Mapa do Inventário Florestal da Vegetação Nativa do Estado de São Paulo-2009. Disponível em: $<$ http://arquivos.ambiente.sp.gov.br/sifesp/2013 /12/mapainventario.pdf>. Acesso em: 4 abr. 2018.
SÃO PAULO. Secretaria do Meio Ambiente de São Paulo. Fundação Florestal. Plano de Manejo da APA Corumbataí, Botucatu e Tejupá - Perímetro Botucatu Vol. I e II. São Paulo: Secretaria de Meio Ambiente, 2011.

SIMON, A. L. H.; TRENTIN, G. Elaboração de cenários recentes de uso da terra utilizando imagens do Google Earth. Ar@cne. Rev. Electrónica de recursos en Internet sobre Geografía y Ciencias Sociales, n. 116, 2009. Disponível em:

http://www.ub.edu/geocrit/aracne/aracne116.htm>. Acesso em: 18 fev. 2018. 